\title{
IMPACT OF AEROSOL ON THE ESTIMATION ACCURACY OF SOLAR RADIATION
}

\author{
Calinoiu Delia-Gabriela $^{1,2}$, Paulescu Marius ${ }^{2}$ \\ ${ }^{1}$ Faculty of Physics, West University of Timisoara, V. Parvan Ave.4, 300223 Timisoara, Romania \\ ${ }^{2}$ Department of Physical Foundations of Engineering, Politehnica University Timisoara, V. Parvan Ave. 2,
} 300223 Timisoara, Romania

\begin{tabular}{|l|l|}
\hline \multicolumn{1}{|c|}{ Article Info } & \multicolumn{1}{c|}{ Abstract } \\
\hline $\begin{array}{l}\text { Received: } 23.07 .2018 \\
\text { Accepted: } 15.08 .2018\end{array}$ & $\begin{array}{l}\text { The paper is focused on the solar irradiance estimation in clear-sky } \\
\text { conditions and an aerosol-loaded atmosphere. Two parametric models developed } \\
\text { by our group and three empirical models are tested. The estimates of the } \\
\text { parametric models are based on three atmospheric parameters (ozone, nitrogen } \\
\text { dioxide and water vapor column content) and the aerosol properties quantified by } \\
\text { Keywords: aerosols, } \\
\text { solar irradiance, clear- } \\
\text { sky. }\end{array}$ \\
$\begin{array}{l}\text { scattering albedo, asymmetry factor). The empirical models contain no inputs for } \\
\text { aerosol properties. Data collected from 10 stations were used to test the models. } \\
\text { The inputs for the parametric models were retrieved from Aerosol Robotic } \\
\text { Network - AERONET. Global and diffuse solar irradiance data at high-quality } \\
\text { standards were retrieved from the Baseline Surface Radiation Network BSRN. A } \\
\text { comparative analysis of the models' accuracy in estimating clear-sky solar } \\
\text { irradiance is discussed from the perspective of aerosol proprieties. }\end{array}$ \\
\hline
\end{tabular}

\section{Introduction}

Various models for estimating solar irradiance under clear-sky conditions have been developed in the last decades. The simplest models are empirical equations, which are fitted on radiometric data collected on a limited spatial region. Three typical models from this class are considered in this study: the Biga and Rosa model [1], Adnot et al. [2] and Empirical Irradiance Model - EIM [3]. Another class of simple clear-sky solar irradiance models comprises the parametric models, which mainly originate from spectral codes. These models take into account the meteorological parameters (such as ozone and nitrogen dioxide column content, water vapor column) and the aerosol properties (by means of several specific parameters: Ångström turbidity coefficient, single scattering albedo, asymmetry factor). Two 
models developed by our team fall in this class: Solar Irradiance Model version 1 - SIM v1 [4] and Solar Irradiance Model version 2-SIM v2 [5] are considered in this study.

In this paper, a comparative analysis on the performance of the five models listed above in estimating clear-sky solar irradiance is reported. All the models, fully described in the original publication, are briefly presented in the next section.

\section{Models description}

The model SIM $v 1$ was developed starting from the Gueymard's spectral code SMARTS2 [6] by averaging the spectral atmospheric transmittances $\tau_{x}(\lambda, \omega)$ in respect to wavelength:

$$
\bar{\tau}_{x}(\omega)=\frac{\int_{0}^{\infty} \tau_{x}(\lambda, \omega) G_{e x t}(\lambda) d \lambda}{\int_{0}^{\infty} G_{e x t}(\lambda) d \lambda}
$$

In Eq. (1) the weights are given by the spectral density of the solar irradiance on top of the atmosphere $G_{e x t}(\lambda)$. The subscript $x$ designates a specific atmospheric attenuator (ozone absorption, nitrogen dioxide absorption, water vapor absorption, mixed gas absorption, Rayleigh scattering and aerosol extinction [4].

The global solar irradiance $G$ is calculated as the sum of beam $G_{b}$ and diffuse $G_{d}$ components:

$$
\begin{aligned}
& G_{b}=G_{S C} \varepsilon \bar{\tau}_{b} \sin h \\
& G_{d}=G_{S C} \varepsilon \bar{\tau}_{d} \sin h
\end{aligned}
$$

where $G_{b}$ and $G_{d}$ are expressed as functions of the sun elevation angle $h, G_{S C}=1366.1 \mathrm{~W} / \mathrm{m}^{2}$ is the solar constant and $\varepsilon$ is the correction factor according to the Sun - Earth distance which can be computed with the Spencer's equation [7]. $\bar{\tau}_{b}$ and $\bar{\tau}_{d}$ stand for the average beam and diffuse atmospheric transmittances, respectively.

SIM v2 represents an upgraded version of SIM v1, aiming to improve the accuracy of estimates in arid environment. The new elements of SIM v2, such as new equations for aerosol absorption and downward fraction, have been introduced targeting to better capture the peculiarities of the solar radiation extinction by aerosols [5]. 
The empirical models contain equations which take into account only the sun elevation angle. A brief description of these models follows.

Biga and Rosa model. Based upon a fitted of radiometric data from Lisbon, the model equations are [1]:

$$
\begin{aligned}
& G_{b}=926 \cdot \sin h^{0.29} \\
& G_{d}=131 \cdot \sin h^{0.6} \\
& G=G_{b} \cdot \sin h+G_{d}
\end{aligned}
$$

Adnot et al. model estimates only the global solar irradiance [2]:

$$
G=951.39 \cdot \sin h^{1.15}
$$

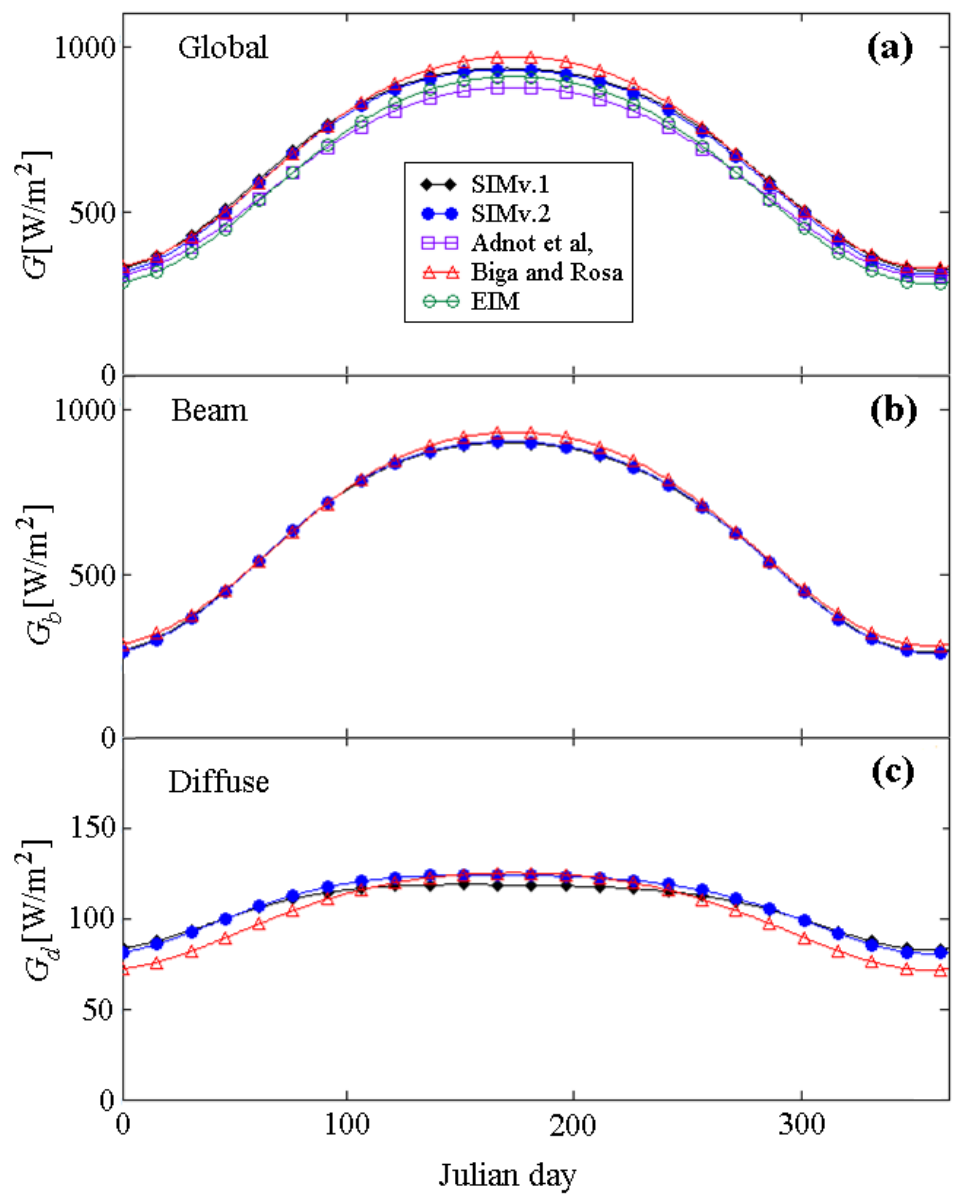

Fig. 1. Estimated solar irradiance components at noon: (a) global, (b) beam and (c) diffuse.

Empirical Irradiance Model - EIM. The model was fitted using data recorded in clearsky condition at the meteorological station of Timisoara [3]. 


$$
G=G_{S C}[1-0.4645 \cdot \exp (-0.69 \cdot \sin h)] \cdot \exp \left(-\frac{0.05211}{\sin h}\right) \cdot \sin h
$$

Figure 1 shows the solar irradiance components estimated by the five models considered in this study. To generate the curves, the models have been run at noon during an entire year, with the following inputs: $45^{\circ} \mathrm{N}$ latitude, $100 \mathrm{~m}$ altitude, $l_{O 3}=0.3434 \mathrm{~atm} \cdot \mathrm{cm}$, $l_{N O 2}=2.04 \cdot 10^{-4} \mathrm{~atm} \cdot \mathrm{cm}$ and $l_{W}=1.419 \mathrm{~cm}$, reference values for U.S. Standard Atmosphere [6]. In addition, the values of Angström turbidity coefficient $\beta=0.079$, single scattering albedo $\varpi=0.9$ and the asymmetry factor $g=0.5$ have been considered. Visual inspection of Fig. 1 shows that for these climatologic parameters the curves generated by SIM v1 and SIM v2 are superimposed. There are some differences between the estimates performed by the simple empirical models and the parametric models. During the summer, the Biga and Rosa model estimates the highest values for global solar irradiance while the Adnot et al. model estimates the lowest values, with a difference of roughly $80 \mathrm{~W} / \mathrm{m}^{2}$. The estimates of SIMv.1 and SIMv.2 are placed in the middle of the interval delimitated by the two curves. Overall, Fig. 1 shows that different clear-sky models estimate different values for solar irradiance. In order to evaluate the models' performances, in the next section the models are tested against measured data.

Table 1. Station used in this study. $N$ represents the number of measurements in clear-sky conditions collected from a station.

\begin{tabular}{llllllllll}
\hline \multirow{2}{*}{$\mathrm{Nr}$} & & & \multicolumn{3}{c}{ BSRN station } & \multicolumn{5}{l}{ AERONET station } \\
\cline { 3 - 8 } & & Country & Location & $\begin{array}{l}\text { Lat. } \\
{[\mathrm{deg}]}\end{array}$ & $\begin{array}{l}\text { Long. } \\
{[\mathrm{deg}]}\end{array}$ & $\begin{array}{l}\text { Alt. } \\
{[\mathrm{m}]}\end{array}$ & $\begin{array}{l}\text { Lat. } \\
{[\mathrm{deg}]}\end{array}$ & $\begin{array}{l}\text { Long. } \\
{[\mathrm{deg}]}\end{array}$ & $\begin{array}{l}\text { Alt. } \\
{[\mathrm{m}]}\end{array}$ \\
\hline 1 & Algeria & Tamanrasset & 22.79 & 5.52 & 1385 & 22.79 & 5.53 & 1377 & 548 \\
2 & Israel & Sede Boqer & 30.85 & 34.77 & 500 & 30.85 & 34.78 & 480 & 548 \\
3 & KSA & Solar Village & 24.91 & 46.41 & 650 & 24.90 & 46.39 & 764 & 424 \\
4 & USA & Tucson & 32.22 & -110.95 & 786 & 32.23 & -110.95 & 779 & 370 \\
5 & Brasil & Petrolina & -9.06 & -40.31 & 387 & -9.38 & -40.50 & 370 & 287 \\
6 & USA & Billings & 36.60 & -97.51 & 317 & 36.60 & -97.48 & 318 & 222 \\
7 & USA & Boulder & 40.05 & -105.00 & 1577 & 40.05 & -105.00 & 1604 & 394 \\
8 & France & Palaiseau & 48.71 & 2.20 & 156 & 48.70 & 2.20 & 156 & 584 \\
9 & France & Carpentras & 44.08 & 5.05 & 100 & 44.08 & 5.05 & 100 & 368 \\
10 & Estonia & Toravere & 58.25 & 26.46 & 70 & 58.25 & 26.46 & 70 & 363 \\
\hline
\end{tabular}




\section{Models performance}

The models have been tested in estimating the clear-sky solar irradiance at 10 radiometric stations. For running the models SIMv1 and SIMv2 the atmospheric parameters and the aerosol optical parameters were retrieved from AErosol RObotic NETwork AERONET [8]. Global and diffuse solar irradiance data was taken from Baseline Surface Radiation Network - BSRN [9]. Data have been collected on basis of two criteria: (i) only data measured in perfectly clear-sky days were considered and, (ii) the location of the AERONET station has to be very close to the location of a BSRN station. At Tucson, the radiometric data were collected from the radiometric station located at the University of Arizona, part of the NREL's network Measurement and Instrumentation Data Center [10]. Table 1 lists the stations, country, their geographical coordinates and the number of measurements.

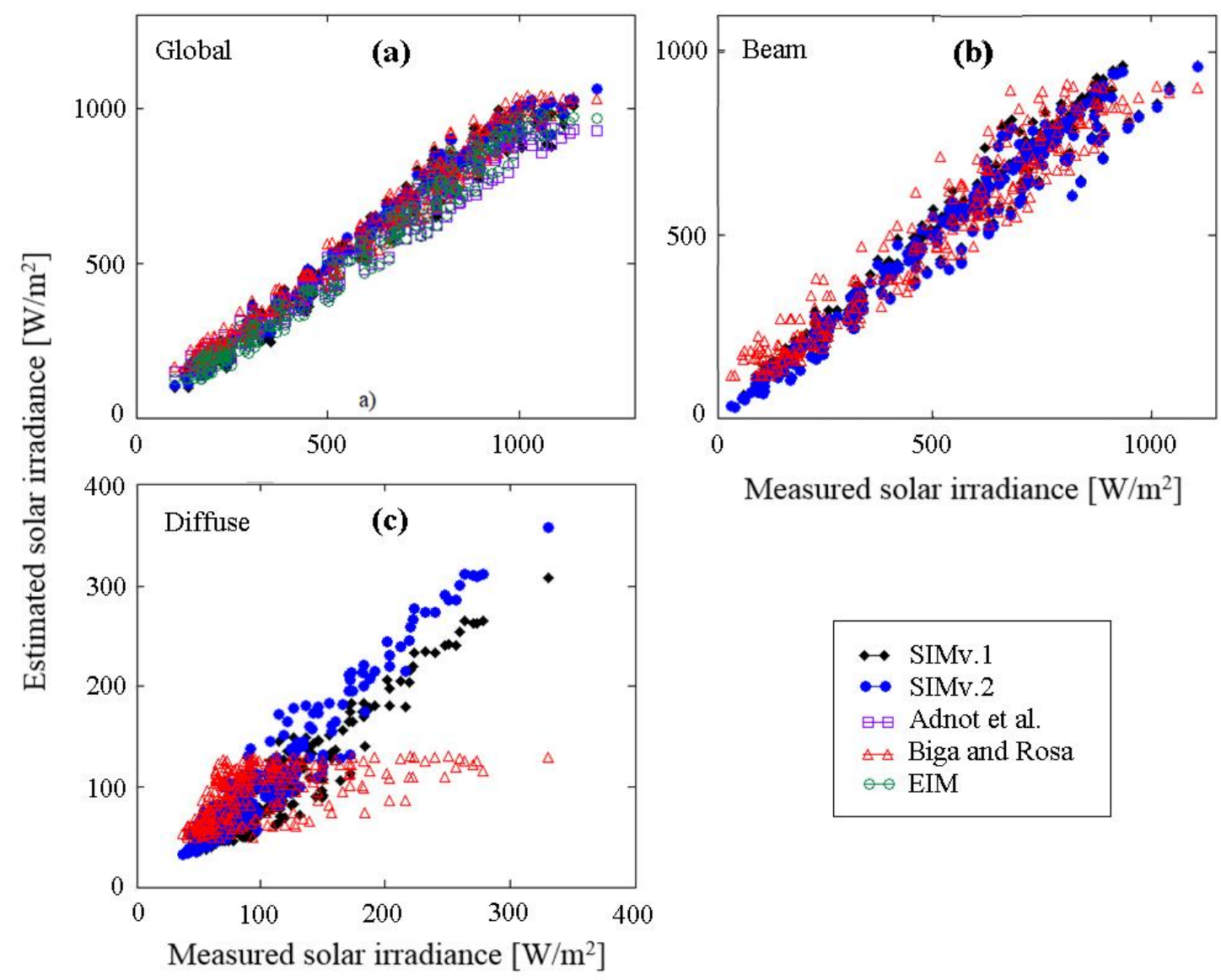

Fig. 2. Estimated vs. measured solar irradiance components: (a) global, (b) beam and (c) diffuse

The models' performance was assessed in terms of two statistical indicators very often used in solar radiation modeling: root mean square error (RMSE) and mean bias error (MBE). 
In order to compare the performances of the models applied to samples with different magnitudes, these indicators were normalized to the sample mean:

$$
\begin{gathered}
n R M S E=\frac{\left[M \sum_{i=1}^{M}\left(c_{i}-m_{i}\right)^{2}\right]^{1 / 2}}{\sum_{i=1}^{M} m_{i}} \\
n M B E=\frac{\sum_{i=1}^{M}\left(c_{i}-m_{i}\right)}{\sum_{i=1}^{M} m_{i}}
\end{gathered}
$$

The subscripts $c$ and $m$ refer to computed and measured values, respectively, while $M$ is the sample size.

Table 2. Performance of the models tested against all measured data

\begin{tabular}{|l|c|c|c|c|c|c|}
\hline Solar irradiance & \multicolumn{2}{|c|}{ Global } & \multicolumn{2}{c|}{ Beam } & \multicolumn{2}{c|}{ Diffuse } \\
\hline Statistical indicator & $\begin{array}{c}n R M S E \\
{[\%]}\end{array}$ & $\begin{array}{c}n M B E \\
{[\%]}\end{array}$ & $\begin{array}{c}n R M S E \\
{[\%]}\end{array}$ & $\begin{array}{c}n M B E \\
{[\%]}\end{array}$ & $\begin{array}{c}n R M S E \\
{[\%]}\end{array}$ & $\begin{array}{c}n M B E \\
{[\%]}\end{array}$ \\
\hline SIMv.1 & 8.08 & -2.79 & 10.55 & -0.54 & 20.75 & -13.64 \\
\hline SIMv.2 & 6.37 & -2.63 & 10.44 & -3.21 & 19.73 & 0.18 \\
\hline Adnot et al. & 13.67 & -9.35 & - & - & - & - \\
\hline Biga and Rosa & 7.85 & -0.54 & 14.39 & 0.85 & 44.36 & -7.23 \\
\hline EIM & 12.65 & -9.63 & - & - & - & - \\
\hline
\end{tabular}

Figure 2 displays a scatter plot of the estimated vs. measured data for the global, beam and diffuse components of solar irradiance. Generally, all the models perform well when estimating the global solar irradiance. Interestingly, the simple models seem to estimate global solar irradiance with the same accuracy as the parametric models. A low performance of the Biga and Rosa model is noticed at the estimation of diffuse solar irradiance. This is due to the lack of inputs for the aerosol optical properties. Table 2 presents the results of assessing the models' accuracy in terms of statistical indicators. Only the Biga and Rosa model achieve an accuracy in estimating global solar irradiance comparable with the parametric models. However, the Biga and Rosa model is not recommended for estimating the diffuse solar irradiance. Overall, the best model is SIMv.2, achieving the lowest values of $n R M S E$ for all the three estimated components. 


\section{Conclusions}

In this paper a comparison of five models for estimating the solar irradiance components under clear sky condition is reported. Empirical models, developed by fitting the measured data, usually collected from a single location, perform comparably with the more sophisticated parametric models in estimating global solar irradiance. Due to their simplicity, empirical equations can be used successfully in many applications where a very high accuracy is not required. The inputs ascribe to the parametric models a general character. The actual information on aerosols provided at the input, allows the parametric models to capture the peculiarities of diffuse solar irradiance.

\section{Acknowledgements}

The authors express their gratitude to the dedicated personnel who maintain the 10 radiometric (BSRN) and photometric (AERONET) stations considered in this study.

\section{References}

[1] A.J. Biga, R. Rosa. Solar Energy 23(1979) 61-67

[2] J. Adnot, B. Bourges, D. Campana, R. Gicquel. Utilisation des courbes de frequence cumulees pour le calcul des installation solaires, In Analise Statistique des Processus Meteorologiques Appliquee a l'Energie Solaire, Lestienne R., Paris (1979)

[3] M. Paulescu, Z. Schlett. Renewable Energy 29(2004) 767-777

[4] D. Calinoiu, M Paulescu, I. Ionel, N. Stefu, N. Pop, R. Bota, A. Pacurar, P. Gavrila, E. Paulescu, G. Trif - Tordai. Energy Conversion and Management 70(2013) 76-82

[5] D. Calinoiu, N. Stefu, R. Bota, R. Blaga, N. Pop, E. Paulescu, A. Sabadus, M. Paulescu. Energy Conversion and Management 164(2018) 175-187

[6] C. Gueymard. SMARTS2, A Simple Model of the Atmospheric Radiative Transfer of Sunshine: Algorithms and performance assessment, FSEC-PF-270-95 (1995)

[7] W. Spencer. Search 2(1971) 172.

[8] Aerosol Robotic Network. https://aeronet.gsfc.nasa.gov/ (Accessed July 2018)

[9] Baseline Surface Radiation Network http://bsrn.awi.de/ (Accessed July 2018)

[10] Measurements and Instrumentations Data Center, NREL. https://midcdmz.nrel.gov/ (Accessed July 2018) 